This manuscript is a preprint which has been submitted for publication. It has not undergone peer review yet.

Subsequent versions of this manuscript may have slightly different content. If accepted, the final version of this manuscript will be available

via the 'Peer-reviewed Publication DOl' link on the right - hand side of this webpage.

Please feel free to contact any of the authors; we welcome feedback. 


\title{
Earthquake rupture on multiple splay faults and its effect on tsunamis
}

\author{
I. van Zelst $^{1,2}$, L. Rannabauer ${ }^{3}$, A.-A. Gabriel ${ }^{4}$, Y. van Dinther ${ }^{1,5}$ \\ ${ }^{1}$ Seismology and Wave Physics, Institute of Geophysics, Department of Earth Sciences, ETH Zürich, \\ Zürich, Switzerland \\ ${ }^{2}$ Institute of Geophysics and Tectonics, School of Earth and Environment, University of Leeds, Leeds, LS2 \\ 9JT, United Kingdom \\ ${ }^{3}$ Department of Informatics, Technical University of Munich, Munich, Germany \\ ${ }^{4}$ Geophysics, Department of Earth and Environmental Sciences, LMU Munich, Munich, Germany \\ ${ }^{5}$ Department of Earth Sciences, Utrecht University, Utrecht, The Netherlands \\ Key Points: \\ - Multiple splay faults can be activated during an earthquake by slip on the megath- \\ rust, dynamic stress transfer, or stress changes from waves \\ - Splay fault activation is partially facilitated by their alignment with the local stress \\ field and closeness to failure \\ - The tsunami has a high crest due to slip on the longest splay fault and a second \\ broad wave packet due to slip on multiple smaller faults
}

Corresponding author: Iris van Zelst, i.vanzelst@leeds.ac.uk / iris.v.zelst@gmail.com 


\section{Abstract}

Detailed imaging of accretionary wedges reveal complex splay fault networks which could pose a significant tsunami hazard. However, the dynamics of multiple splay fault activation and interaction during megathrust events and consequent effects on tsunami generation are not well understood. We use a 2D dynamic rupture model with six complex splay fault geometries consistent with initial stress and strength conditions constrained by a geodynamic seismic cycle model. The dynamic seafloor displacements serve as input for a 1D shallow water tsunami propagation and inundation model. We find that all splay faults rupture coseismically due to either slip on the megathrust, dynamic stress transfer, or stress changes induced by seismic waves. The ensuing tsunami features one high-amplitude crest related to rupture on the longest splay fault and a second, broader wave packet resulting from slip on the other faults. This results in two episodes of flooding and $77 \%$ larger run-up length.

\section{Plain Language Summary}

In subduction zones, where one tectonic plate moves beneath another, earthquakes can occur on many different faults. Splay faults are steep faults that branch off the largest fault in a subduction zone (the megathrust). As they are steeper than the megathrust, the same amount of movement on them could result in more vertical displacement of the seafloor. Therefore, splay faults are thought to play an important role in the generation of tsunamis. Here, we use computer simulations to study if an earthquake can break multiple splay faults at once and what the effect of this is on the tsunami. We find that multiple splay faults can indeed fail during a single earthquake, due to the complicated stress changes that occur during the rupture. Rupture on splay faults result in larger seafloor displacements with smaller wavelengths, so the ensuing tsunami is bigger and results in two main flooding episodes at the coast.

\section{Introduction}

Splay faults branch off the megathrust in the accretionary wedge or overriding plate (e.g., Plafker, 1965; Fukao, 1979; Park et al., 2002). Earthquake ruptures originating on the megathrust can potentially transfer to splay faults. Apart from complicating rupture dynamics, this may lead to important ramifications for tsunamigenesis, as rupture 
on splay faults increases the efficiency of tsunami generation (e.g., Fukao, 1979; Lotto et al., 2018; Hananto et al., 2020). Several studies suggested that splay fault rupture played an important role in large tsunamigenic megathrust earthquakes, such as the $2004 M_{w} 9.1-$ 9.3 Sumatra-Andaman and $2010 M_{w}$ 8.0 Maule earthquakes (DeDontney \& Rice, 2012; Melnick et al., 2012; Waldhauser et al., 2012). Tsunami earthquakes in which the observed tsunami is larger than expected from surface wave magnitude analysis of the earthquake (e.g., Kanamori, 1972; Heidarzadeh, 2011), such as the 365 Crete, 1946 Nankai, and 1964 Alaska earthquakes, have also been linked to splay fault rupture (e.g., Cummins \& Kaneda, 2000; Cummins et al., 2001; Shaw et al., 2008; Chapman et al., 2014; Haeussler et al., 2015; von Huene et al., 2016; Fan et al., 2017; Martin et al., 2019; Hananto et al., 2020; Suleimani \& Freymueller, 2020).

Dynamic rupture modelling is a useful tool to understand the role of splay faults in rupture dynamics (e.g., Kame et al., 2003; Wendt et al., 2009; Geist \& Oglesby, 2009; DeDontney et al., 2011; Tamura \& Ide, 2011; DeDontney \& Hubbard, 2012; Lotto et al., 2018). These studies show that parameters such as the initial stress, branching angle, frictional properties, strength of the accretionary wedge, and material contrasts along the megathrust affect splay fault rupture. Building upon these insights, several coupled models have been employed to solve for splay fault rupture dynamics and tsunamis sequentially or simultaneously (Wendt et al., 2009; Geist \& Oglesby, 2009; Li et al., 2014; Lotto et al., 2018).

Dynamic rupture models of branching faults typically use simple, planar fault geometries, even if observed splay fault geometries are much more complicated (e.g, Park et al., 2002; G. Moore et al., 2007; Collot et al., 2008). Besides that, most dynamic rupture studies include only a single splay fault, which is partly necessitated by the difficulty of modelling fault junctions with numerical methods (e.g., Aochi et al., 2002; DeDontney et al., 2012). Observations of accretionary wedges in subduction zones show multiple splay faults with a range of sizes and dips, although not all of them are expected to be seismically active simultaneously (G. F. Moore et al., 2001; Kimura et al., 2007; Kopp, 2013; Fabbri et al., 2020; Hananto et al., 2020).

To understand the effect of multiple splay fault rupture with non-planar geometries on the surface displacements and the ensuing tsunami, we model dynamic rupture 
constrained by a geodynamic model of long-term subduction and the subsequent tsunami propagation and inundation.

\section{Modelling approach}

We use the modelling approach presented in Van Zelst et al. (2019), where a geodynamic seismic cycle (SC) model is used to constrain the initial conditions of a dynamic rupture (DR) model. We extend this approach by using the resulting surface displacements of the DR model as input for a tsunami propagation and inundation (TS) model. Our modelling framework accounts for the varying temporal and spatial scales from geodynamics to tsunami inundation (see also Madden et al., 2020). We apply this framework to the problem of multiple splay fault rupture by including six splay fault geometries constrained by the SC model in the DR model setup.

\subsection{Geodynamic seismic cycle model}

The SC model solves for the conservation of mass, momentum, and energy with a visco-elasto-plastic rheology (Gerya \& Yuen, 2007). It models 4 million years of subduction followed by a seismic cycle phase with a 5-year time step with spontaneous slip events driven by a strongly rate-dependent seismo-thermo-mechanical (STM) modelling approach (van Dinther et al., 2013). We observe widespread visco-plastic shear bands in the accretionary wedge in the SC model during slip events, which we interpret as faults (Figure 1a). For one event, we use the output of the SC model as input for the DR model according to Van Zelst et al. (2019). We pick six splay fault geometries according to the highest accumulated visco-plastic strain during the event visualised as the accumulated visco-plastic slip in Figure 1a (Supplementary Material Section S1; Figures S1-S7). The splay faults generally align with the local stress field (Figure 1b) and are close to failure, apart from splay fault (SF) 6 and the deeper parts of SF4 and SF5 (Figures S8-15). The branch angles (average 14.4 ${ }^{\circ}$ ) and dips (average 24.0 $0^{\circ}$ ) of our splay fault geometries are in line with observations (Park et al., 2002) and other modelling studies (Table S1; Wendt et al., 2009; DeDontney et al., 2011; Tamura \& Ide, 2011; DeDontney \& Hubbard, 2012). 

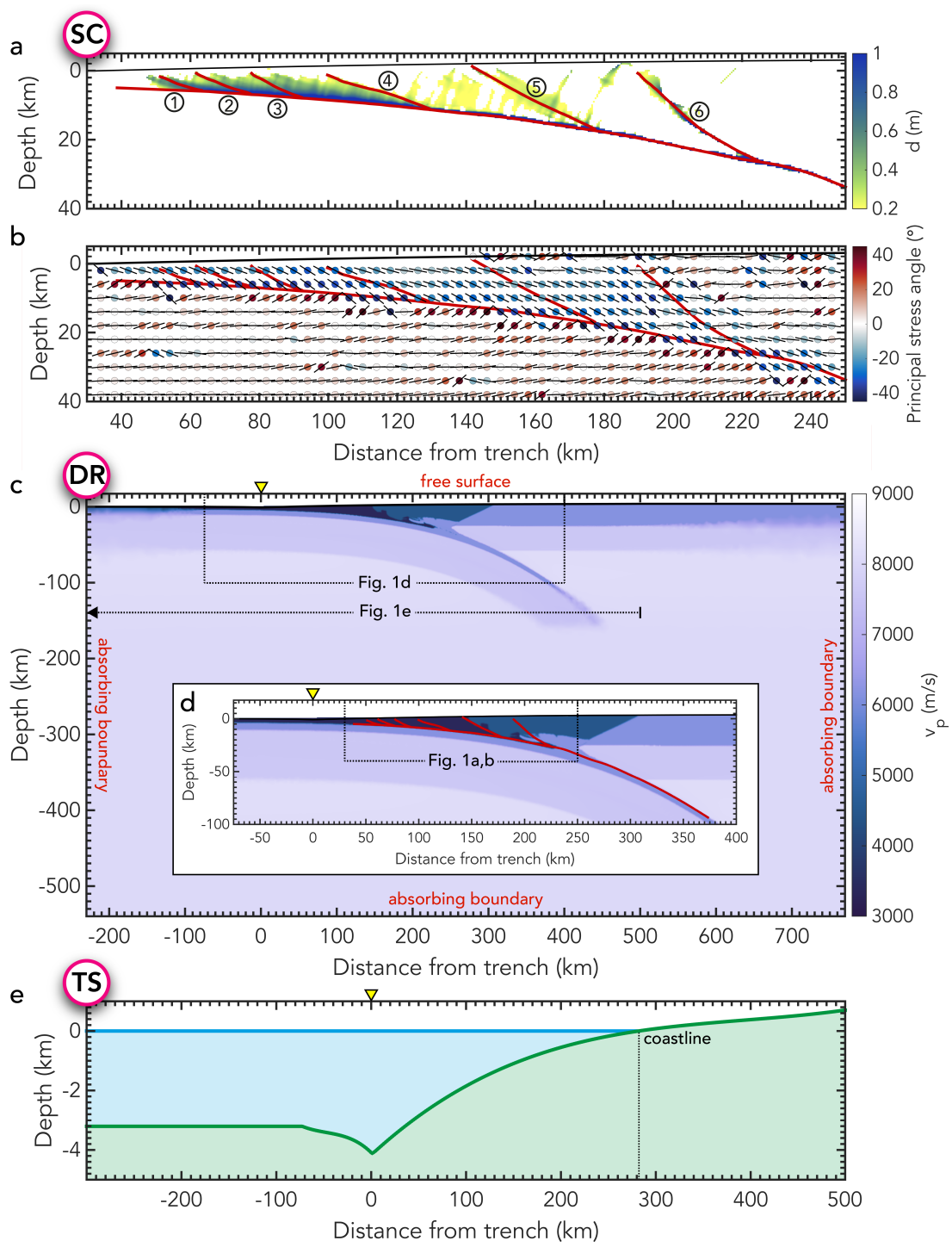

Figure 1. (a) Accumulated slip $d$ in the accretionary wedge after the SC slip event from Van Zelst et al. (2019). Picked splay fault geometries (red) are numbered for easy reference. (b) Orientation of the principal stress $\sigma_{1}$ in the SC model. The angle is indicated in colour and by the bar originating in each dot. Complete (c) and zoomed (d) model setup of the DR model with $P$-wave velocity $v_{p}$, boundary conditions (red) and megathrust and splay fault geometries. (e) Model setup of the tsunami propagation and inundation model with bathymetry (green) and initial sea surface height (blue). The coastline is located at $x=282.25 \mathrm{~km}$. Note that the $x$-axis differs for each panel depending on the model setup size (trench indicated by the yellow triangle).

\subsection{Dynamic rupture model}

We use the two-dimensional version of the software package SeisSol (http://www .seissol.org; Dumbser \& Käser, 2006; de la Puente et al., 2009; Pelties et al., 2014) 
to model dynamic rupture in the model setup described by Van Zelst et al. (2019) with six additional splay fault geometries in the mesh (Figure 1c,d). We model mode II fracture, which is a simplification that is also used by other studies (e.g., Ramos \& Huang, 2019). The on-fault element edge length is $200 \mathrm{~m}$, which combined with polynomial degree $p=5$ (spatio-temporal order 6 accuracy for wave propagation) results in an effective resolution of $28.6 \mathrm{~m}$ on the fault, which is sufficient to resolve the cohesive zone size. At the top of the DR model setup, we employ a free surface boundary condition with topography derived from a $3^{\text {rd }}$ order polynomial approximation of the rock-sticky air (Crameri et al., 2012) interface in the SC model from $x=-72.8 \mathrm{~km}$ to $x=499.6 \mathrm{~km}$, beyond which we assign constant topography values (Figure 1e). We run the model for $180 \mathrm{~s}$, which ensures smooth coupling to the TS model, as the surface displacements do not vary significantly after that time. To obtain the surface displacements of the DR model, we place 601 seismometers from $-100 \mathrm{~km}$ to $500 \mathrm{~km}$ near the free surface with a spacing of $1 \mathrm{~km}$ to record the velocity field.

\subsection{Tsunami propagation and inundation model}

To model tsunami propagation, we use the one-dimensional shallow water equations (SWE), which consist of the conservation of mass and momentum and consider the hydro-static pressure caused by gravitational acceleration (Madden et al., 2020). Other tsunami studies sometimes use the hydrodynamic shallow water equations (e.g., Wendt et al., 2009; Saito et al., 2019). We choose a hydrostatic approach, since we are specifically interested in the combination of dynamic tsunami generation and inundation.

To solve the SWEs, we employ a first order finite volume scheme (LeVeque et al., 2002) and we use a well-tested augmented Riemann solver to solve for inundation (George, 2008). To incorporate dynamic surface displacements, we consider the bathymetry as a time-dependent parameter. We define the bathymetry as the unperturbed topography from the SC model which has an average beach angle of $7.2 \cdot 10^{-6}$. Then we add the seafloor deformation $\Delta b(x, t)$, caused by the displacements from the DR model. To compute the seafloor deformation from the DR model we use the method by Tanioka and Satake (1996), which adds the vertical displacement to a linear approximation of the contribution of the horizontal displacement. The resulting displacement field contains fast travelling seismic waves, which are radiating from the earthquake source during the DR simulation. We remove the seismic waves from all displacements used as tsunami sources. To this 
end, we apply a Fourier filter to the seafloor displacements which removes transient displacements resulting from waves with a frequency/wavelength ratio higher than $300 \mathrm{~m} / \mathrm{s}$ (Figures S18-19).

We consider a model domain from $x=-300 \mathrm{~km}$ to $x=500 \mathrm{~km}$, with the initial bathymetry from the SC model (Figure 1e). We set the coastline at $x=282.25 \mathrm{~km}$ to coincide with the downdip limit of the seismogenic zone (Klingelhoefer et al., 2010). This results in a maximum water depth of $4117 \mathrm{~m}$. To discretise the model, we use 20,000 points, which translates to an average spacing of $40 \mathrm{~m}$. We use adaptive time stepping and run the model for a total simulation time of 2 hours with maximum time steps of $0.5 \mathrm{~s}$ and minimum time steps of $0.08 \mathrm{~s}$. We consider cells with a water column of less than $10^{-6} \mathrm{~m}$ as dry.

\section{Results}

\subsection{Dynamic earthquake rupture}

We compare a model in which only the megathrust is allowed to rupture (Figure 2a; Van Zelst et al. (2019)) to the model in which six splay faults are theoretically allowed to break. The ruptures show similar rupture speeds, but different rupture duration with the model including splay faults rupturing for longer (89 s instead of $82 \mathrm{~s}$ ). Approximating the magnitude of the ruptures with the empirical rupture width-magnitude scaling by Blaser et al. (2010), results in $M_{w}=9.4$ for the model without splays and $M_{w}=$ 9.8 for the model including them. However, this does not take the amount of slip into account, which differs significantly between the two ruptures with the model including splay faults exhibiting lower slip and slip velocities (Figure 2).

After a non-prescribed two-stage nucleation at very low slip rate (a $4 \mathrm{~s}$ period of low rupture speed, followed by a $2 \mathrm{~s}$ high speed phase), spontaneous rupture emerges on the megathrust ((1) in Figure 2b) and the rupture propagates both updip and downdip, where the rupture is spontaneously arrested at the brittle-ductile transition (2) in both models (Figure 2a,b). In the updip direction, the main rupture front in the splay fault model encounters SF6 after $14.1 \mathrm{~s}$. While the dynamic activation of SF6 appears to resemble rupture branching (DeDontney et al. (2011); Movie 1, 2 in Supplementary Material), we observe a high degree of complexity on smaller scales. The passing megathrust rupture dynamically unclamps $\mathrm{SF} 6$, i.e., there is a decrease in the normal stress $\sigma_{n}$ 

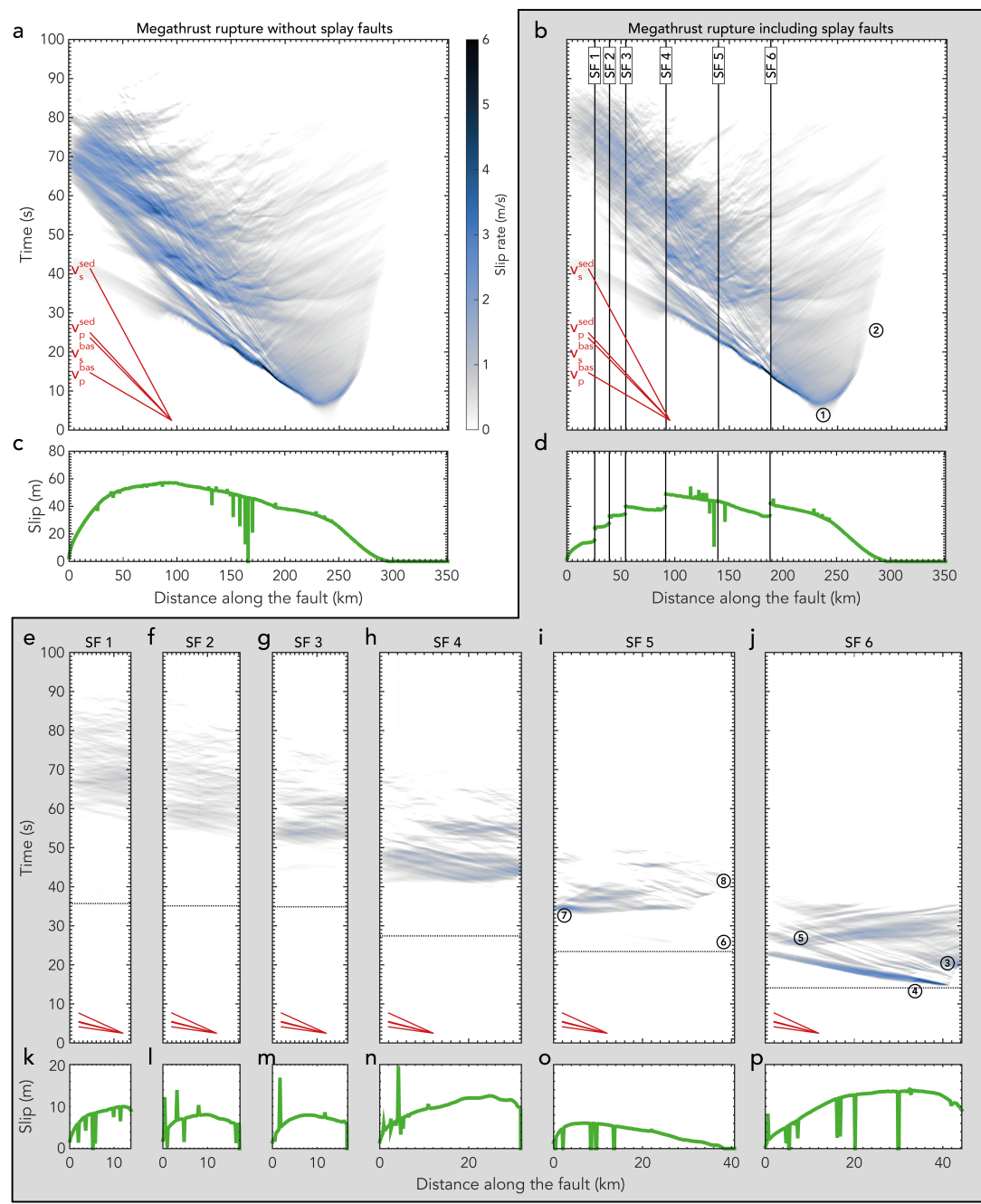

Figure 2. (a,b) Slip rate evolution with time along the megathrust fault for the model (a) without splay faults and (b) including the six splay fault geometries. The splay fault branching points on the megathrust are indicated by black lines. (c,d) Accumulated slip on the megathrust. (e-j) Slip rate evolution and (k-p) accumulated slip on each of the six splay faults for the model including the splay faults. The splay faults connect to the megathrust at the right of each panel. Horizontal black dotted lines indicate the passing of the megathrust rupture front at the branching point. The $P$ - and $S$-wave velocities for the basalt and sediment are indicated in red: $v_{p}^{\text {bas }}=6164 \mathrm{~m} / \mathrm{s}, v_{s}^{\text {bas }}=3559 \mathrm{~m} / \mathrm{s}, v_{p}^{\text {sed }}=4429 \mathrm{~m} / \mathrm{s}, v_{s}^{\text {sed }}=2557 \mathrm{~m} / \mathrm{s}$. See text for an explanation of the numbers.

(Oglesby et al., 2008), which results in negligible slip over $1 \mathrm{~km}$ of the splay fault close to the fault junction without spontaneously propagating rupture. Subsequently the rupture jumps from the megathrust to SF6 due to dynamic triggering, omitting the deep- 
est $3 \mathrm{~km}$ of the splay fault, which only ruptures in a down-dip direction after $18 \mathrm{~s}((3)$ in Figure 2j). Unilateral dynamic rupture then propagates updip on the splay fault with slip velocities of $4.7 \mathrm{~m} / \mathrm{s}$. Simultaneously, in front of this rupture front, secondary ruptures are dynamically triggered by the main megathrust rupture (4) leading to an apparently very high updip splay rupture speed. Behind the first, apparently fast splay rupture front, we observe fault reactivation due to multiple passing rupture fronts on the megathrust and free surface reflected seismic waves (5), resulting in a static slip maximum of $13.8 \mathrm{~m}$. Due to the splay fault rupture, the slip velocities on the megathrust updip of the splay fault are sharply reduced compared to a model which only ruptures the megathrust. This leads to a slip discontinuity on the megathrust (Figure 2d).

The main rupture front on the megathrust passes SF5 without activating it (6), i.e., neither by branching nor dynamic triggering (Figure 2i). Instead, SF5 is activated at $\sim 5 \mathrm{~km}$ depth at $32.8 \mathrm{~s}$ due to waves reflecting from the surface (7). Multiple rupture fronts then propagate downdip on SF5, but the deepest $2.5 \mathrm{~km}$ of SF5 never fully rupture (8). Since the passing of the primary megathrust rupture front does not trigger slip on SF5, there is no decrease in slip rate on the megathrust after it passes SF5.

Although the passing of the main rupture front induces small slip rates on SF14 on the order of $\sim 0.02 \mathrm{~m} / \mathrm{s}$ due to unclamping, they only rupture self-sustained afterwards at slip rates larger than $1 \mathrm{~m} / \mathrm{s}$ due to the static and dynamic stress changes induced by secondary rupture front complexity on the megathrust as well as on SF5 and SF6 and multiple reflected (trapped) waves within the accretionary wedge. The long rupture duration on these shallow splay faults leads to a maximum slip of $12.6 \mathrm{~m}$ for SF4 and $10.0 \mathrm{~m}, 8.1 \mathrm{~m}$, and $8.0 \mathrm{~m}$ for SF1-3, respectively, barring any numerical outliers. Since slip occurs on the splay faults and the slip velocity on the megathrust is reduced when the rupture interacts with a splay fault, the maximum slip on the megathrust in the model including splay fault rupture $(48.9 \mathrm{~m})$ is lower than in the model without splay fault rupture $(57.6 \mathrm{~m})$. Besides that, the slip profile on the megathrust is discontinuous and corresponds to rupture on the splay faults.

The maximum stress drop on the megathrust on the order of $\sim 17 \mathrm{MPa}$ is comparable in the models with and without splay faults (Figure S16). Splay fault 6 shows the largest stress drop of all splay faults on the order of $\sim 19 \mathrm{MPa}$. The other splay faults 


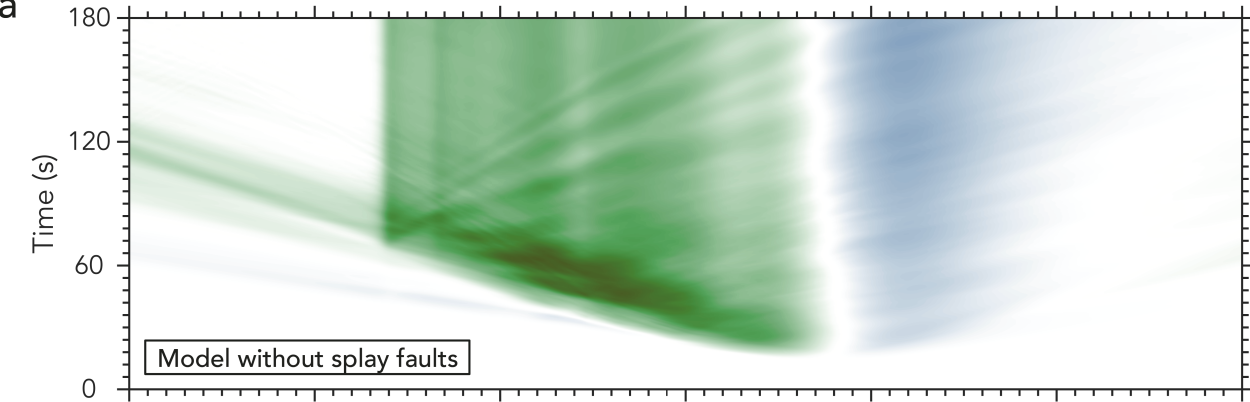

b
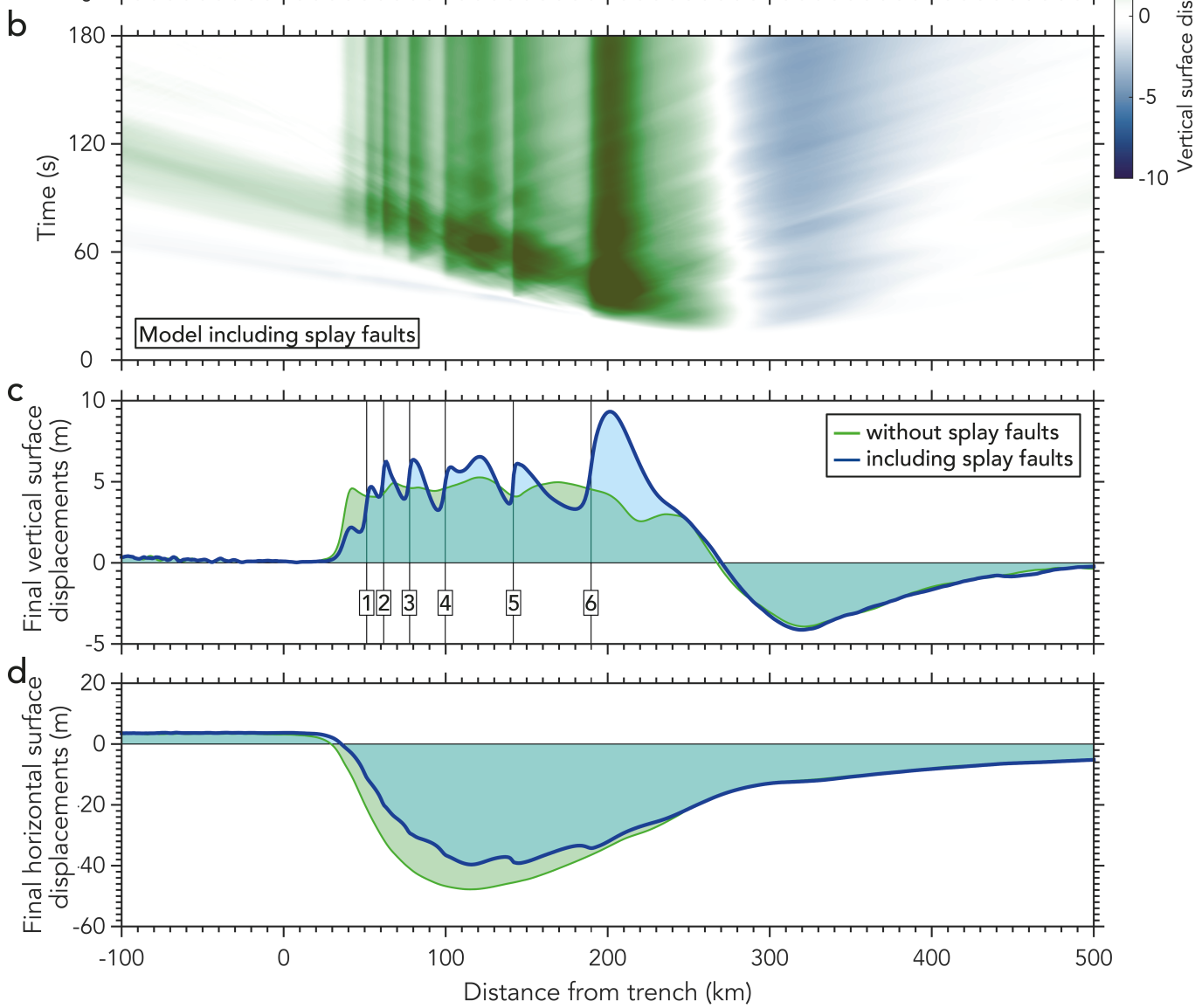

Figure 3. (a,b) Temporal evolution of the vertical surface displacements in the model (a) without splay faults and (b) including all six splay fault geometries. The static vertical (c) and horizontal (d) surface displacements of the two models after $180 \mathrm{~s}$ are compared in $(\mathrm{c}, \mathrm{d})$ with splay fault numbers indicating the $x$-coordinates of the shallow splay fault tips near the surface.

show maximum stress drops of 2.5-6.5 MPa, with the deeper splay faults exhibiting larger stress drops than the shallow splay faults.

The model without splay faults has relatively uniform static vertical surface displacements of $\sim 5 \mathrm{~m}$ and a smooth profile of horizontal displacements of $47.8 \mathrm{~m}$ sea- 
wards (Figure 3). In contrast, the model with splay faults shows clear vertical surface displacement peaks corresponding to the shallow tips of the splay faults near the surface (Figure 3b,c). The wavelengths of these peaks are $\sim 80-95 \%$ smaller than the wavelengths of the vertical surface displacements due to rupture purely on the megathrust. The largest peak of $9.3 \mathrm{~m}$ at $180 \mathrm{~s}$ is associated with SF6, whereas the other peaks with amplitudes ranging from 4.7-6.5 $\mathrm{m}$ are associated with SF1-5. Hence, rupture on splay faults increases the amplitude of the vertical displacements with up to $86 \%$. The amounts of vertical displacement and slip are not linearly correlated (Figure S17) as other factors, such as the dip angle and slip distribution on the fault also play a role. The effect of splay fault rupture is less pronounced in the horizontal displacements with a $17 \%$ lower amplitude of the horizontal displacements compared to the model without splay faults (Figure 3d).

\subsection{Tsunami propagation and inundation}

The tsunami resulting from the model without splay faults consists of a single wave with a wavelength of $300 \mathrm{~km}$ and a maximum sea surface height of $6.5 \mathrm{~m}$ (Figure 4a). It arrives at the beach after $11 \mathrm{~min}$ and it takes a total of $74.5 \mathrm{~min}$ for the whole wave to arrive at the coast. There is one episode of flooding at the coast with a run-up length of $1250 \mathrm{~m}$. In the model including splay fault rupture, the tsunami consists of one high wave crest corresponding to slip on SF6 ((7) in Figure 4b) and a broad wave packet resulting from slip on the other splay faults and shallow limit of the megathrust ((1-6) in Figure $4 \mathrm{~b}$ ). Similar to the tsunami of the model without splay faults, the waves span a region of $300 \mathrm{~km}$, but have smaller individual wavelengths. The tsunami first reaches the coast after $11 \mathrm{~min}$ and impacts the coast until $71.3 \mathrm{~min}$. It reaches a maximum sea surface height of $12.2 \mathrm{~m}$, which is almost double the height of the model without splay faults. Besides that, the flooding at the coast occurs in two episodes (Figure 4e) in contrast to one flooding episode for the model without splay faults. The first episode is related to the large wave resultant from rupture on SF6, whereas the second episode relates to a wave originating from the interference of the smaller waves related to the other splay faults and shallow megathrust. The run-up length of the tsunami is $2210 \mathrm{~m}$, which is $77 \%$ larger than that of the tsunami sourced by a rupture without splay faults. 

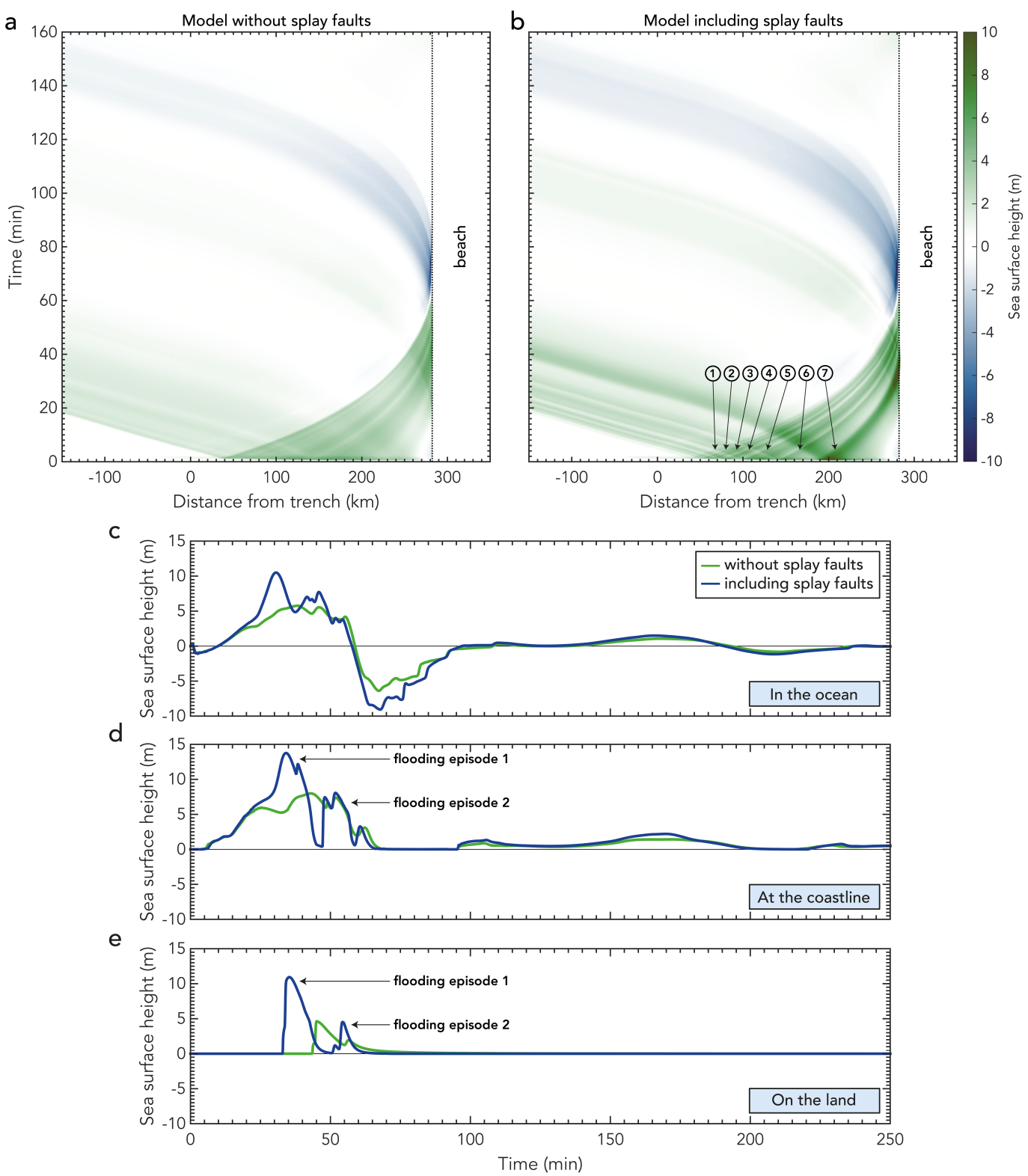

Figure 4. Temporal evolution of the sea surface height for (a) the model without splay faults and (b) the model including all six splay faults. (c,d,e) Sea surface height with time at three different locations for both the model without (green) and with (blue) splay faults: (c) $x=278.46 \mathrm{~km}$, in the ocean; (d) $x=282.46 \mathrm{~km}$, at the coastline; (e) $x=283.46 \mathrm{~km}$, on the beach. As the measurements are taken on land in (d,e), the sea surface height should be interpreted as inundation depth.

\section{Discussion}

Observational studies of accretionary wedges image multiple splay faults which pose a tsunami hazard (Kopp, 2013). However, it is difficult to asses if multiple splay faults 
will rupture during a single earthquake and how that would affect the ensuing tsunami. The choice of numerical discretisation method typically hampers the geometric complexity in dynamic rupture models (e.g., DeDontney \& Hubbard, 2012). Here, we explicitly account for the complex geometries of a shallowly dipping megathrust intersecting with several splay faults.

Our models show that all six splay faults rupture when we use the self-consistent initial conditions from the SC model. This is partly due to the predominantly optimal orientation of the splay faults with respect to the local stress field (Figure 1b). In line with this, the splay faults exhibit low strength excess (Figures S10-S15) — particularly at shallow depths - indicating that they are close to failure (Li et al., 2014). Here, we define strength excess as $\sigma_{\text {yield }}^{\mathrm{dr}}-\tau$, where $\sigma_{\text {yield }}^{\mathrm{dr}}$ is the fault yield stress and $\tau$ is the initial shear stress. The low strength excess of the shallow splay faults partly results from the weak, i.e., low static friction coefficient, sediments of the accretionary wedge where high pore-fluid pressures are prevalent (van Dinther et al., 2014). The deeper splay faults SF4-6 are not as close to failure as the shallower splay faults, but still rupture due to the energetic rupture and wave reflections and the resulting stress changes. SF5 in particular does not rupture at the branching point due to the large strength excess and high branching angle $\left(21.8^{\circ}\right)$. Instead, it is activated at shallow depth due to reflecting waves from the surface where the strength excess on the fault is small. Hence, our results suggest that multiple splay faults rupture during an energetic event with reflecting waves when they are well orientated with respect to the local stress field, i.e., they are strong faults according to Andersonian faulting theory, and have a low strength excess, i.e., they are close to failure.

In the tsunami models, the effect of slip on splay faults is visible in the propagating wave and the inundation pattern at the coast (Figure 4; Goda et al. (2014)). The tsunami model without splay fault rupture also shows localised crests (Figure 4a), although to a lesser extent. This indicates that crests in the tsunami data cannot exclusively be contributed to splay fault rupture. Similarly, the absence of complexity in the tsunami data or source inversion, particularly with regards to the second wave packet, does not necessarily mean that rupture only occurred on one splay fault. Indeed, the effect of rupture on other, smaller splay faults might not be distinguishable based on tsunami data alone. To relate our findings to tsunami data, the here found splay fault effects should be analysed with more complex bathymetry and 3D complexity in future studies (Matsuyama 
et al., 1999; Bletery et al., 2015; Ulrich et al., 2019; Madden et al., 2020; Tonini et al., 2020).

\section{Conclusions}

In this study, we develop and use one of the first modelling frameworks that combines geodynamics, seismic cycles, dynamic rupture, and tsunamis. We can therefore constrain the geometry, stress, and strength of the domain, megathrust, and six splay faults in a physically self-consistent manner. We find that the splay faults are optimally orientated with respect to the local stress field - unlike the shallow megathrust — which contributes to splay fault rupture. The splay faults are activated by various mechanisms, such as the passing of the megathrust rupture front and stress changes from reflected waves in the accretionary wedge. Rupture on the largest splay fault in our simulations results in a short-wavelength increase in tsunami height. A second, broad wave packet in the tsunami is due to slip on multiple smaller faults and the shallow megathrust, making it difficult to distinguish from the tsunami data alone if multiple splay faults ruptured. In order to better understand tsunami hazard, future studies should take the possibility of rupture on multiple splay faults into account as it has an effect on the tsunami height and flooding pattern at the coast.

\section{Acknowledgements}

We warmly thank Stephanie Wollherr, Thomas Ulrich, Casper Pranger, and Andreas Fichtner for sharing their expertise on the SC and DR models with us. We also thank the Tectonics Group at the University of Leeds for helpful comments and discussion that improved this manuscript. We are much obliged to Sebastian Rettenberger, who originally wrote the tsunami code.

We use scientific colour maps by Crameri (2018b) to prevent visual distortion of the data and exclusion of readers with colour-vision deficiencies (Crameri, 2018a).

We used the computational resources of the ETH cluster Euler. This work is part of the ASCETE-II project (Advanced Simulation of Coupled Earthquake-Tsunami Events) funded by the Volkswagen Foundation grant 88479. Additionally, IvZ was funded by the Royal Society (UK) through Research Fellows Enhancement Award RGF $\backslash E A \backslash 181084$. 


\section{Author contribution statement}

IvZ conceived the study, designed and ran the DR models, analysed the DR and TS results, and wrote the article. LR designed the tsunami models together with IvZ and ran them. YvD and AAG supervised IvZ and contributed to the analysis of the SC and DR models. All authors discussed the results and contributed to the final manuscript.

\section{Data availability statement}

We use the data of the geodynamic seismic cycle model provided in Van Zelst et al. (2019) to set up our dynamic rupture model. The additional six splay fault geometries can be found in the supplementary material of this article and will be uploaded to Zenodo. We use the two-dimensional version of the open source software package SeisSol to model dynamic rupture (http://www.seissol.org). We use the one-dimensional version of the open source code SWE to model the tsunami (https://github.com/TUM -I5/SWE), which will also be made available on Zenodo.

\section{References}

Aochi, H., Madariaga, R., \& Fukuyama, E. (2002). Effect of normal stress during rupture propagation along nonplanar faults. Journal of Geophysical Research: Solid Earth, 107(B2), ESE-5.

Blaser, L., Krüger, F., Ohrnberger, M., \& Scherbaum, F. (2010). Scaling relations of earthquake source parameter estimates with special focus on subduction environment. Bulletin of the Seismological Society of America, 100(6), 2914-2926.

Bletery, Q., Sladen, A., Delouis, B., \& Mattéo, L. (2015). Quantification of tsunami bathymetry effect on finite fault slip inversion. Pure and Applied Geophysics, 172(12), 3655-3670.

Chapman, J. B., Elliott, J., Doser, D. I., \& Pavlis, T. L. (2014). Slip on the suckling hills splay fault during the 1964 alaska earthquake. Tectonophysics, 637, 191197.

Collot, J.-Y., Agudelo, W., Ribodetti, A., \& Marcaillou, B. (2008). Origin of a crustal splay fault and its relation to the seismogenic zone and underplating at the erosional north ecuador-south colombia oceanic margin. Journal of Geophysical Research: Solid Earth, 113(B12).

Crameri, F. (2018a). Geodynamic diagnostics, scientific visualisation and StagLab 
3.0. Geoscientific Model Development, 11(6), 2541-2562.

Crameri, F. (2018b). Scientific colour-maps. Zenodo. Retrieved from http://doi .org/10.5281/zenodo.1243862 doi: http://doi.org/10.5281/zenodo.1243862

Crameri, F., Schmeling, H., Golabek, G. J., Duretz, T., Orendt, R., Buiter, S. J. H., .. Tackley, P. J. (2012). A comparison of numerical surface topography calculations in geodynamic modelling: an evaluation of the 'sticky air' method. Geophysical Journal International, 189(1), 38-54.

Cummins, P. R., Hori, T., \& Kaneda, Y. (2001). Splay fault and megathrust earthquake slip in the nankai trough. Earth, planets and space, 53(4), 243-248.

Cummins, P. R., \& Kaneda, Y. (2000). Possible splay fault slip during the 1946 nankai earthquake. Geophysical Research Letters, 27(17), 2725-2728.

DeDontney, N., \& Hubbard, J. (2012). Applying wedge theory to dynamic rupture modeling of fault junctions. Bulletin of the Seismological Society of America 102(4), 1693-1711.

DeDontney, N., \& Rice, J. R. (2012). Tsunami wave analysis and possibility of splay fault rupture during the 2004 Indian Ocean earthquake. Pure and applied geophysics, 169(10), 1707-1735.

DeDontney, N., Rice, J. R., \& Dmowska, R. (2011). Influence of material contrast on fault branching behavior. Geophysical Research Letters, 38(14).

DeDontney, N., Rice, J. R., \& Dmowska, R. (2012). Finite element modeling of branched ruptures including off-fault plasticity. Bulletin of the Seismological Society of America, 102(2), 541-562.

de la Puente, J., Ampuero, J.-P., \& Käser, M. (2009). Dynamic rupture modeling on unstructured meshes using a discontinuous Galerkin method. Journal of Geophysical Research: Solid Earth, 114(B10).

Dumbser, M., \& Käser, M. (2006). An arbitrary high-order discontinuous Galerkin method for elastic waves on unstructured meshes-II. The three-dimensional isotropic case. Geophysical Journal International, 167(1), 319-336.

Fabbri, O., Goldsby, D., Chester, F., Karpoff, A., Morvan, G., Ujiie, K., .. o others (2020). Deformation Structures From Splay and Décollement Faults in the Nankai Accretionary Prism, SW Japan (IODP NanTroSEIZE Expedition 316): Evidence for Slow and Rapid Slip in Fault Rocks. Geochemistry, Geophysics, Geosystems, 21(6), e2019GC008786. 
Fan, W., Bassett, D., Jiang, J., Shearer, P. M., \& Ji, C. (2017). Rupture evolution of the 2006 Java tsunami earthquake and the possible role of splay faults. Tectonophysics, 721, 143-150.

Fukao, Y. (1979). Tsunami earthquakes and subduction processes near deep-sea trenches. Journal of Geophysical Research: Solid Earth, 84(B5), 2303-2314.

Geist, E. L., \& Oglesby, D. D. (2009). Tsunamis: Stochastic models of occurrence and generation mechanisms. In R. A. Meyers (Ed.), Encyclopedia of complexity and systems science (pp. 1-29). New York, NY: Springer New York. Retrieved from https://doi.org/10.1007/978-3-642-27737-5_595-1 doi: 10 .1007/978-3-642-27737-5_595-1

George, D. L. (2008). Augmented Riemann solvers for the shallow water equations over variable topography with steady states and inundation. Journal of Computational Physics, 227(6), 3089-3113.

Gerya, T. V., \& Yuen, D. A. (2007). Robust characteristics method for modelling multiphase visco-elasto-plastic thermo-mechanical problems. Physics of the Earth and Planetary Interiors, 163(1), 83-105.

Goda, K., Mai, P. M., Yasuda, T., \& Mori, N. (2014). Sensitivity of tsunami wave profiles and inundation simulations to earthquake slip and fault geometry for the 2011 Tohoku earthquake. Earth, Planets and Space, 66(1), 105.

Haeussler, P. J., Armstrong, P. A., Liberty, L. M., Ferguson, K. M., Finn, S. P., Arkle, J. C., \& Pratt, T. L. (2015). Focused exhumation along megathrust splay faults in Prince William Sound, Alaska. Quaternary Science Reviews, $113,8-22$.

Hananto, N., Leclerc, F., Li, L., Etchebes, M., Carton, H., Tapponnier, P., .. Wei, S. (2020). Tsunami earthquakes: Vertical pop-up expulsion at the forefront of subduction megathrust. Earth and Planetary Science Letters, 538, 116197.

Heidarzadeh, M. (2011). Major tsunami risks from splay faulting. The Tsunami Threat-Research and Technology, 67-80.

Kame, N., Rice, J. R., \& Dmowska, R. (2003). Effects of prestress state and rupture velocity on dynamic fault branching. Journal of Geophysical Research: Solid Earth, 108(B5).

Kanamori, H. (1972). Mechanism of tsunami earthquakes. Physics of the earth and planetary interiors, 6(5), 346-359. 
Kimura, G., Kitamura, Y., Hashimoto, Y., Yamaguchi, A., Shibata, T., Ujiie, K., \& Okamoto, S. (2007). Transition of accretionary wedge structures around the up-dip limit of the seismogenic subduction zone. Earth and Planetary Science Letters, $255(3-4), 471-484$.

Klingelhoefer, F., Gutscher, M.-A., Ladage, S., Dessa, J.-X., Graindorge, D., Franke, D., ... Chauhan, A. (2010). Limits of the seismogenic zone in the epicentral region of the 26 December 2004 great Sumatra-Andaman earthquake: Results from seismic refraction and wide-angle reflection surveys and thermal modeling. Journal of Geophysical Research: Solid Earth, 115(B1).

Kopp, H. (2013). Invited review paper: The control of subduction zone structural complexity and geometry on margin segmentation and seismicity. Tectonophysics, 589, 1-16.

LeVeque, R. J., et al. (2002). Finite volume methods for hyperbolic problems (Vol. 31). Cambridge university press.

Li, S., Moreno, M., Rosenau, M., Melnick, D., \& Oncken, O. (2014). Splay fault triggering by great subduction earthquakes inferred from finite element models. Geophysical Research Letters, 41(2), 385-391.

Lotto, G. C., Jeppson, T. N., \& Dunham, E. M. (2018). Fully Coupled Simulations of Megathrust Earthquakes and Tsunamis in the Japan Trench, Nankai Trough, and Cascadia Subduction Zone. Pure and Applied Geophysics, 1-33.

Madden, E., Bader, M., Behrens, J., Van Dinther, Y., Gabriel, A.-A., Rannabauer, L., .. Van Zelst, I. (2020). Linked 3-D modelling of megathrust earthquaketsunami events: from subduction to tsunami run up. Geophysical Journal International, 224(1), 487-516.

Martin, S. S., Li, L., Okal, E. A., Morin, J., Tetteroo, A. E., Switzer, A. D., \& Sieh, K. E. (2019). Reassessment of the 1907 Sumatra tsunami earthquake based on macroseismic, seismological, and tsunami observations, and modeling. Pure and Applied Geophysics, 176(7), 2831-2868.

Matsuyama, M., Walsh, J., \& Yeh, H. (1999). The effect of bathymetry on tsunami characteristics at Sisano Lagoon, Papua New Guinea. Geophysical Research Letters, 26(23), 3513-3516.

Melnick, D., Moreno, M., Motagh, M., Cisternas, M., \& Wesson, R. L. (2012). Splay fault slip during the Mw 8.82010 Maule Chile earthquake. Geology, 40(3), 
$251-254$

Moore, G., Bangs, N., Taira, A., Kuramoto, S., Pangborn, E., \& Tobin, H. (2007). Three-dimensional splay fault geometry and implications for tsunami generation. Science, 318(5853), 1128-1131.

Moore, G. F., Taira, A., Klaus, A., Becker, L., Boeckel, B., Cragg, B. A., .. others (2001). New insights into deformation and fluid flow processes in the Nankai Trough accretionary prism: Results of Ocean Drilling Program Leg 190. Geochemistry, Geophysics, Geosystems, 2(10).

Oglesby, D. D., Mai, P. M., Atakan, K., \& Pucci, S. (2008). Dynamic models of earthquakes on the North Anatolian fault zone under the Sea of Marmara: Effect of hypocenter location. Geophysical Research Letters, 35(18).

Park, J.-O., Tsuru, T., Kodaira, S., Cummins, P. R., \& Kaneda, Y. (2002). Splay fault branching along the Nankai subduction zone. Science, 297(5584), 11571160.

Pelties, C., Gabriel, A.-A., \& Ampuero, J.-P. (2014). Verification of an ADER-DG method for complex dynamic rupture problems. Geoscientific Model Development, $7(3), 847-866$.

Plafker, G. (1965). Tectonic deformation associated with the 1964 Alaska earthquake. Science, 148(3678), 1675-1687.

Ramos, M. D., \& Huang, Y. (2019). How the transition region along the Cascadia megathrust influences coseismic behavior: Insights from 2-D dynamic rupture simulations. Geophysical Research Letters, 46(4), 1973-1983.

Saito, T., Baba, T., Inazu, D., Takemura, S., \& Fukuyama, E. (2019). Synthesizing sea surface height change including seismic waves and tsunami using a dynamic rupture scenario of anticipated Nankai trough earthquakes. Tectonophysics, 228166 .

Shaw, B., Ambraseys, N., England, P., Floyd, M., Gorman, G., Higham, T., .. Piggott, M. (2008). Eastern Mediterranean tectonics and tsunami hazard inferred from the AD 365 earthquake. Nature Geoscience, 1(4), 268-276.

Suleimani, E., \& Freymueller, J. T. (2020). Near-field modeling of the 1964 Alaska tsunami: the role of splay faults and horizontal displacements. Journal of Geophysical Research: Solid Earth, e2020JB019620.

Tamura, S., \& Ide, S. (2011). Numerical study of splay faults in subduction zones: 
The effects of bimaterial interface and free surface. Journal of Geophysical Research: Solid Earth, 116(B10).

Tanioka, Y., \& Satake, K. (1996). Tsunami generation by horizontal displacement of ocean bottom. Geophysical Research Letters, 23(8), 861-864.

Tonini, R., Basili, R., Maesano, F. E., Tiberti, M. M., Lorito, S., Romano, F., ... Volpe, M. (2020). Importance of earthquake rupture geometry on tsunami modelling: the Calabrian Arc subduction interface (Italy) case study. Geophysical Journal International, 223(3), 1805-1819.

Ulrich, T., Vater, S., Madden, E. H., Behrens, J., van Dinther, Y., Van Zelst, I., ... Gabriel, A.-A. (2019). Coupled, physics-based modeling reveals earthquake displacements are critical to the 2018 Palu, Sulawesi Tsunami. Pure and Applied Geophysics, $176(10)$, 4069-4109.

van Dinther, Y., Gerya, T. V., Dalguer, L. A., Mai, P. M., Morra, G., \& Giardini, D. (2013). The seismic cycle at subduction thrusts: Insights from seismothermo-mechanical models. Journal of Geophysical Research: Solid Earth, $118(12), 6183-6202$.

van Dinther, Y., Mai, P. M., Dalguer, L. A., \& Gerya, T. V. (2014). Modeling the seismic cycle in subduction zones: The role and spatiotemporal occurrence of off-megathrust earthquakes. Geophysical Research Letters, 41(4), 1194-1201.

Van Zelst, I., Wollherr, S., Gabriel, A.-A., Madden, E. H., \& van Dinther, Y. (2019). Modeling megathrust earthquakes across scales: One-way coupling from geodynamics and seismic cycles to dynamic rupture. Journal of Geophysical Research: Solid Earth, 124(11), 11414-11446.

von Huene, R., Miller, J. J., Klaeschen, D., \& Dartnell, P. (2016). A possible source mechanism of the 1946 Unimak Alaska far-field tsunami: uplift of the midslope terrace above a splay fault zone. In Global tsunami science: Past and future, volume $i$ (pp. 4189-4201). Springer.

Waldhauser, F., Schaff, D. P., Diehl, T., \& Engdahl, E. R. ～(2012). $\quad$ Splay faults imaged by fluid-driven aftershocks of the $2004 \mathrm{Mw} 9.2$ Sumatra-Andaman earthquake. Geology, 40(3), 243-246.

Wendt, J., Oglesby, D. D., \& Geist, E. L. (2009). Tsunamis and splay fault dynamics. Geophysical Research Letters, 36(15). 